\title{
APLICAÇÃO DO ÍNDICE DE VEGETAÇÃO POR DIFERENÇA NORMALIZADA (NDVI) PARA AVALIAÇÃO AMBIENTAL DA BACIA HIDROGRÁFICA DO ALTO GUARIROBA, CAMPO GRANDE-MS
}

\author{
José Lucas Ferreira Martins ${ }^{1}$
}

\author{
Mauro Henrique Soares da Silva²
}

\begin{abstract}
RESUMO
Índices de vegetação são utilizados para descrever a evolução fenológica da cobertura vegetal, é extraído de imagens de alta resolução temporal. Através destes índices são obtidas informações a respeito da quantidade de biomassa verde e dos parâmetros de crescimento e desenvolvimento da vegetação. Este estudo objetivou principalmente, avaliar a situação atual em comparação com a de anos passados da Bacia Hidrográfica do Alto Guariroba, localizada dentro da Área de Preservação Ambiental do Manancial do Rio Guariroba, em Campo Grande, Mato Grosso do Sul, através do Índice de Vegetação Por Diferença Normalizada (NDVI). Desta forma pretendeu-se representar a evolução do índice de vegetação ao longo do tempo, do espaço e compreender se a implantação da APA trouxe influencias positivas ou negativas para área estudada. Foram usadas Imagens LANDSAT TM 7 e LANDSAT LC 8 dos anos de 2004 e 2014 respectivamente, as quais foram geoprocessadas em ambiente SIG, por meio do software Spring. Por fim os resultados mostraram que pode ter havido uma conscientização dos moradores da região, pois nos últimos dez anos observou-se um pequeno aumento da vegetação arbórea densa em detrimento de uma área significativa de cerrado em regeneração na bacia. Contudo, o aumento do solo exposto revela uma deficiência nas atividades agropastoris, que perde espaço na mesma proporção que o aumento do solo exposto na APA. Assim devido ao mau uso como herança histórica antes da implantação da APA os corpos hídricos da região, sobretudo a represa principal, podem estar impactados com assoreamentos provenientes das erosões hídricas nos solos desprotegidos da área.
\end{abstract}

PALAVRAS-CHAVE: Cobertura Vegetal. Uso do Solo. Geoprocessamento.

\footnotetext{
${ }^{1}$ Acadêmico do Curso de Agronomia, Universidade ANHANGUERA UNIDERP, Bolsista Voluntário de Iniciação Científica, lucas.martins@uniderp.edu.br

${ }^{2}$ Doutor em Geografia, Universidade ANHANGUERA UNIDERP, Professor Titular, mauro.soares@uniderp.edu.br
} 


\title{
APPLICATION OF NORMALIZED DIFFERENCE VEGETATION INDEX (NDVI) TO ENVIRONMENTAL ANALYSIS OF THE ALTO GUARIROBA WATERSHED, CAMPO GRANDE-MS.
}

\begin{abstract}
Vegetation index are used to describe the phenological evolution of the vegetal cover, it is taken from images with high temporal resolution. Through these indexes, information is got from the quantity of green biomass and from the growth parameters and vegetation development. The objective of this study was evaluate the real situation comparing to past years of Alto Guariroba watershed located inside the Environmental Preservation Area of Guariroba river fountainhead, in Campo Grande-MS through the normalized difference vegetation index (ndvi), this way it is intended to represent the evolution of vegetation index over time, space and understand if implementation of APA brought positive or negative influence to the studied area. It was used LANDSAT 7 and LANDSAT 8 images from the years 2004 to 2014 respectively, which were geo-processed in SIG environment by Spring software. Finally the results showed that it could have been some awareness from the inhabitants of the region, because in the past ten years a small growth of the high tree-shrub vegetation in detriment of a significant area of the savannah forests in regeneration in the area. However, the increase in the exposed soil reveals some deficiency in the agro pastoral activities which loses ground at the same proportion that the exposed soil increases in APA. So due to the badly use of historical heritage just before the implementation of APA the water bodies of the region, mainly, the main reservoir can be impacted with river depredations coming from the water erosion in the unprotected soil of the area.
\end{abstract}

KEYWORD: Vegetal Cover. Use Of The Soil. Geo-Processing

\section{APLICACIÓN DEL INDICE DE VEGETACIÓN POR DIFERENCIA NORMALIZADA (NVDI) PARA LA EVALUACIÓN AMBIENTAL DE LA CUENCA HIDROGRÁFICA DEL ALTO GUARIROBA, CAMPO GRANDE-MS}

\begin{abstract}
RESUMEN
Los índices de vegetación son utilizados para describir la evolución fenológica de la cobertura vegetal y son extraídos de imágenes de alta resolución temporal. A través de estos índices se pueden obtener informaciones sobre la cantidad de biomasa verde y los parámetros de crecimiento y desarrollo de la vegetación. El objetivo principal de este estudio fue evaluar la situación actual en comparación con la de años anteriores de la Cuenca Hidrográfica del Alto Guariroba, localizada dentro del Área de Preservación Ambiental del Manantial del Rio Guariroba en Campo Grande, Mato Grosso del Sur. Haciendo uso del Índice de Vegetación por Diferencia Normalizada (NDVI), fue posible representar la evolución del índice de vegetación a lo largo del tiempo y del espacio, y comprender sí la implantación del APA aportó influencias positivas o negativas para el área estudiada. Fueron utilizadas imágenes LANDSAT 7 y LANDSAT 8 de los años 2004 y 2014 respectivamente, las cuales fueron geoprocesadas en ambiente SIG, por medio del software Spring. Finalmente, los resultados mostraron que puede haber sucedido una concientización de los residentes de la región, pues durante los últimos 10 años se observó un pequeño aumento de la vegetación arbórea densa en expensas de un área considerable de cerrado en regeneración. Aun así, el aumento del suelo expuesto revela la deficiencia en las actividades agro pastorales, que pierden espacio en la misma proporción que aumenta la del suelo expuesto en la APA. Debido al mal uso como herencia histórica antes de la implantación del APA, los
\end{abstract}


cuerpos hídricos de la región, destacando la represa principal, pueden encontrarse afectados por sedimentación proveniente de erosiones hídricas en los suelos desprotegidos del área.

PALABRAS- CLAVE: Cobertura Vegetal. Uso del Suelo. Geoprocesamiento

\section{INTRODUÇÃO}

Os índices de vegetação são importantes ferramentas geradas por técnicas de sensoriamento remoto que têm sido amplamente empregados em diversos trabalhos que buscam relacionar as informações captadas pelos sensores com a vegetação presente na área imageada. Através destes índices são obtidas informações a respeito da quantidade de biomassa verde e dos parâmetros de crescimento e desenvolvimento da vegetação (Firmino et. al., 2009).

Um índice de vegetação resulta da combinação dos valores de reflectância em dois ou mais intervalos de comprimento de onda, possuindo uma relação com a quantidade e o estado da vegetação em uma dada área da superfície terrestre. Em função disto, uma característica inerente aos índices de vegetação é a redução no volume dos dados a ser analisado, pois praticamente toda a informação referente à vegetação fica resumida a somente um valor numérico. Este fato facilita o monitoramento e o estudo do crescimento/desenvolvimento da vegetação, e, também, uma eventual inserção dessa informação em modelos agrometeorológicos-espectrais de estimativa de rendimento de culturas agrícolas (Rizzi, 2004).

Por ser uma tecnologia rápida no processamento dos dados, e principalmente mais acessível financeiramente, o sensoriamento vem sendo importante para estudos ambientais, a fim de ter uma análise bem detalhada sobre o objeto de estudo.

Para Ponzoni (2001) os índices de vegetação devem satisfazer uma série de critérios, tais como: maximizar os parâmetros biofísicos, normalizar efeitos externos, minimizar a contaminação da influência do solo, conduzir a geração de produtos que permitam a comparação das condições de vegetação em escalas globais.

O mapeamento da vegetação na superfície terrestre tem recebido grande destaque devido aos diversos índices de vegetação utilizados nas mais diferentes fitofisionomias representativas dos biomas mundiais. Entre estes índices, tem se 
destacado o Índice de Vegetação por Diferença Normalizada (NDVI) (Oliveira et al., 2010).

O NDVI tem sido utilizado para detectar os efeitos da sazonalidade, o estágio fenológico da vegetação, duração do período de crescimento, pico de verde, mudanças fisiológicas das folhas e períodos de senescência (Ponzoni e Shimabukuro, 2007). A avaliação da cobertura vegetal através dos índices faz-se necessária para monitorar as mudanças sazonais e interanuais no desenvolvimento e na atividade da vegetação e para verificar a ocorrência de estresse hídrico (Jensen, 2009).

O objetivo principal da pesquisa é de avaliar a situação atual em comparação com a de anos passados da Bacia Hidrográfica do Alto Guariroba localizada dentro da Área de Preservação Ambiental do Manancial do Córrego Guariroba, em Campo Grande, Mato Grosso do Sul, por meio da aplicação do Índice de Vegetação Por Diferença Normalizada (NDVI). Desta forma pretende-se representar a evolução do índice de vegetação ao longo do tempo e do espaço, correlacionando com o uso e ocupação do solo, de modo a compreender se a implantação da APA cumpriu com suas funções objetivas trazendo consequências positivas para o meio ambiente na área estudada.

\section{METODOLOGIA DO TRABALHO}

\section{Área de estudo}

Atualmente, com base na Lei Federal N. ${ }^{\circ}$ 9.985, de 18 de julho de 2000, que instituiu o Sistema Nacional de Unidades de Conservação da Natureza (SNUC), a Área de Proteção Ambiental (APA) constitui uma categoria de Unidade de Conservação de Uso Sustentável, onde podem coexistir o desenvolvimento de atividades produtivas exploradoras de recursos naturais e os objetivos de preservação dos atributos naturais e/ou paisagísticos.

Criada no ano de 1995 e com área total aproximada de $360 \mathrm{Km} 2$, a região de estudo é o território da APA do Guariroba, localizado no município de Campo Grande, em Mato Grosso do Sul, sendo caracterizada essencialmente pela ocupação rural, com propriedades voltadas à pecuária extensiva. Atualmente, mais de $82 \%$ do 
Volume 10, Número 2, 2014

Bacias Hidrográficas, Planejamento e Gestão dos Recursos Hídricos

território da APA são ocupados por pastagens artificiais. (Prefeitura Municipal De Campo Grande, 2008).

A bacia hidrográfica do Alto Guariroba, nosso alvo de estudo (figura 1), referese a um recorte espacial da área de nascente do córrego Guariroba, com extensão territorial de aproximadamente $82,3 \mathrm{Km}^{2}$, contemplando, portanto, uma das Sub Bacias deste sistema fluvial responsável pelo abastecimento principal de água potável da Cidade de Campo Grande, MS.

Figura 1 - Localização da Área de Estudo

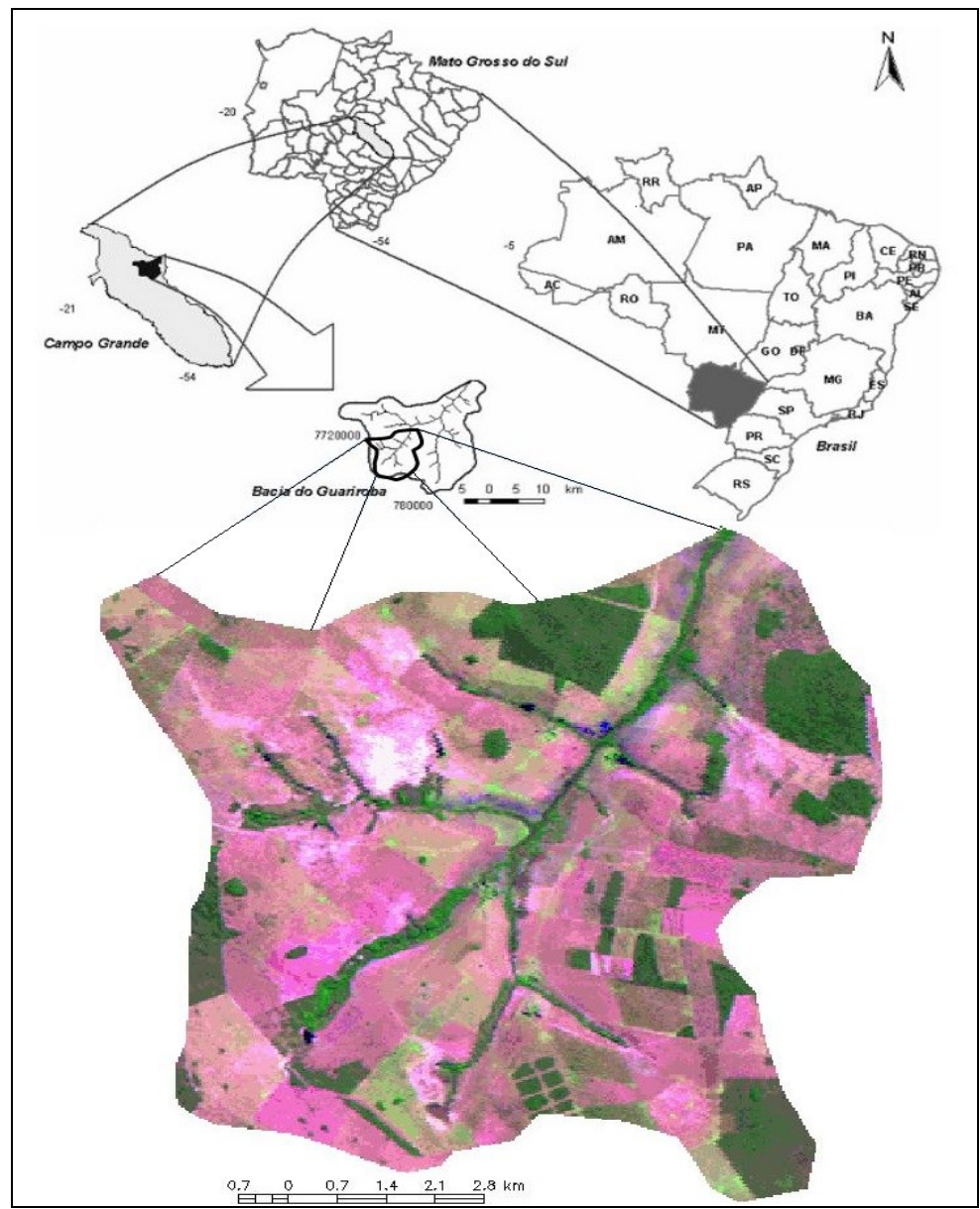

Fonte: Yamaciro (2007) e imagem LANDSAT 5 orbita e ponto 225/74 de 18/05/2004.

\section{Obtenção dos dados e Geoprocessamento de Imagens de Satélites}


Através das geotecnologias, sobretudo com o uso do SIG, de acordo com Florenzano (2001) é possível integrar informações adquiridas da análise de imagens de satélites e calcular as taxas de desmatamento. Moreira (2007) afirma que um índice de vegetação resulta de transformações lineares da refletância obtida em duas ou mais bandas do espectro eletromagnético, mediante soma, razão entre bandas, diferença, ou qualquer outra combinação os dados de reflectância dos alvos podem ser transformados em índices de vegetação, os quais foram criados com o intuito de ressaltar o comportamento espectral da vegetação em relação ao solo e a outros alvos, sendo o Índice de Vegetação por Diferença Normatizada (NDVI) um dos mais comumente usados.

Deste modo, as imagens utilizadas nessa pesquisa, são dos satélites LANDSAT TM5 e LANDSAT LC8, as quais foram adquiridas via internet pelo site do Instituto Nacional de Pesquisas Espaciais - INPE e do U.S. Geological Survey USGS respectivamente. Tais imagens foram capturadas pelos referidos satélites em 18/05/2004 e 09/05/2014 na Orbita 225, Ponto 74.

A partir destes dados brutos, as imagens foram processadas em ambiente SIG, por meio do software Spring, onde as bandas 3, 4 e 5 da imagem LANDSAT TM5 foram realçadas e associadas em composição colorida $B, G$ e $R$ respectivamente, bem como as bandas 4,5 e 6 da imagem LANDSAT LC 8 também foram realçadas e associadas em composição colorida $B, G$ e $R$ respectivamente, formando imagens sintéticas. Com base em uma imagem georreferenciada, as imagens a serem processadas foram registradas.

Por meio do uso de uma Imagem JPEG, contendo as curvas de nível da bacia do Córrego Guariroba, foi delimitada a área da bacia do Alto Guariroba e, por meio da elaboração de um arquivo shapefille com os limites adquiridos, foi realizado o recorte da área de estudo nas bandas das imagens de satélites, as quais foram posteriormente utilizada para a aplicação do NDVI.

Para a análise da distribuição da cobertura vegetal da área estudada, o NDVI foi calculado através da seguinte equação: $N D V I=I V P-V / I V P+V$, onde IVP é valor da reflectância da banda no Infravermelho próximo e $V$ é o valor de reflectância da banda no vermelho. 
Uma vez obtendo-se o arquivo matricial com o NDVI da área recortada, realizou-se o fatiamento das imagens em dez classes distintas correlacionando a reflectância dos pixels em tons de cinza (entre 0 a 255), com um índice de vegetação que variou de -1 a 1 , onde os valores próximos de -1 caracterizam alvos com inexistência de biomassa verde e os valores próximos a 1 indicaram alto grau de biomassa verde.

Assim no processamento da imagem NDVI, a equação aritmética usada no computo é aplicada diretamente sobre cada par de pixels nas bandas do vermelho e infravermelho próximo, produzindo um valor (razão) pertencente ao intervalo de -1 a +1 ou 0 a 255. Quanto mais próximo de 1 ou 255 maior é a certeza de estar se tratando de um pixel de vegetação e os valores mais baixos, indicam a ausência de vegetação. Desta forma foram elaboradas as cartas de NDVI para melhor visualização dos resultados.

Posteriormente foram feitas atividades de campo, entre os dias 24 e 25 de Junho de 2014, onde foram visitados 16 pontos de observação para que se pudesse avaliar a verdade real da área estudada. Assim foi possível elaborar uma chave de interpretação com as imagens do Spring, Google Earth e imagens reais do terreno (Figura 2), na qual o objetivo era tirar as duvidas existente e facilitar na identificação de classes. 
Volume 10, Número 2, 2014

Bacias Hidrográficas, Planejamento e Gestão dos Recursos Hídricos

Figura 1: Chave de Interpretação da Bacia Hidrográfica do Alto Guariroba

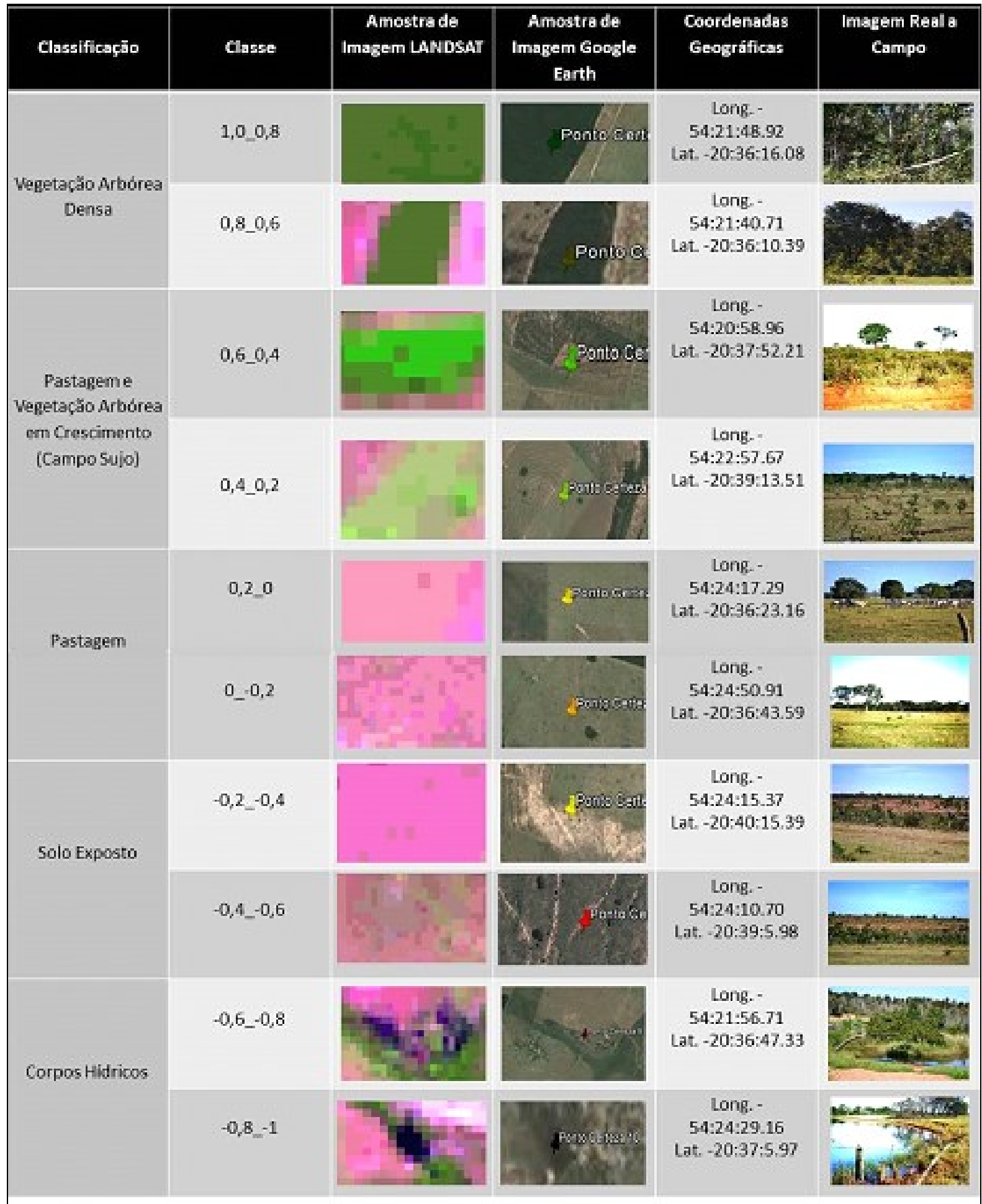


Volume 10, Número 2, 2014

Bacias Hidrográficas, Planejamento e Gestão dos Recursos Hídricos

\section{Resultados e discussão}

Para maior clareza de interpretação, nas duas imagens os intervalos utilizados para as classes do NDVI foram os mesmos, sendo eles divididos em dez classes que vão de 1 á -1 , os quais apresentam classes maiores são referentes a vegetação arbórea densa ou vegetação arbórea em crescimento e os de classes menores aos solos expostos ou copos hídricos.

$\mathrm{Na}$ figura 3 é possível verificar o predomínio das pastagens ocupando $50,9 \mathrm{~km}^{2}$ da área. Também se observa uma grande área de vegetação arbórea em crescimento com $18,7 \mathrm{~km}^{2}$, seguida do solo exposto compondo $10,2 \mathrm{Km}^{2}$, vegetação arbórea densa com $2 \mathrm{Km}^{2}$ e corpo hídrico com $0,5 \mathrm{Km}^{2}$.

$\mathrm{Na}$ Imagem NDVI de 2014 o predomínio também é das pastagens com $49 \mathrm{Km}^{2}$, seguida pela vegetação arbórea em crescimento que apesar de ter decaído ainda apresenta a segunda maior área com $17,5 \mathrm{Km}^{2}$, solo exposto apresenta área de 12,5 $\mathrm{Km}^{2}$, vegetação arbórea densa com $2,8 \mathrm{~km}^{2}$ e corpos hídricos com $0,5 \mathrm{Km}^{2}$, período esse onde já é evidenciado a implantação da Área de Proteção dos Mananciais do Guariroba como Unidade de Conservação.

Figura 3: NDVI da Bacia Hidrográfica do Alto Guariroba para ano de 2004

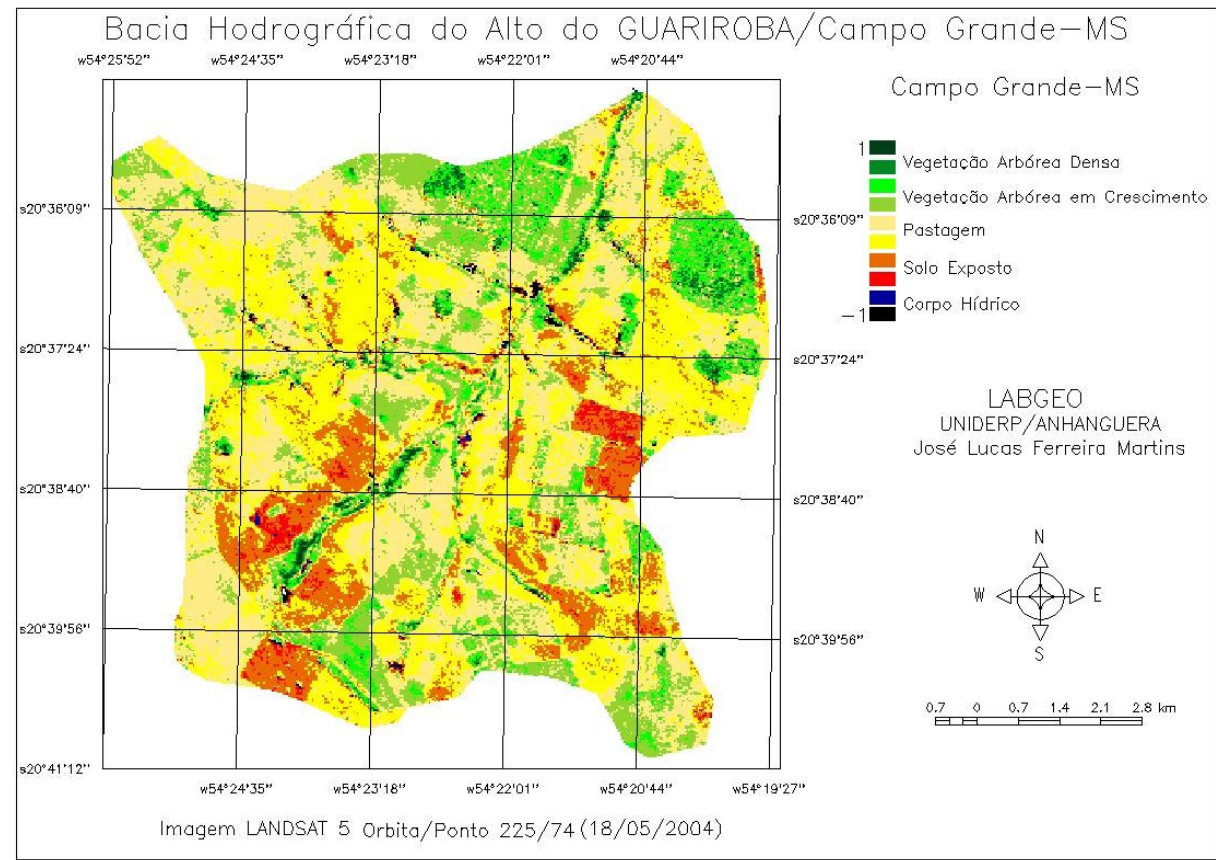


Figura 4: NDVI da Bacia Hidrográfica do Alto Guariroba para ano de 2014

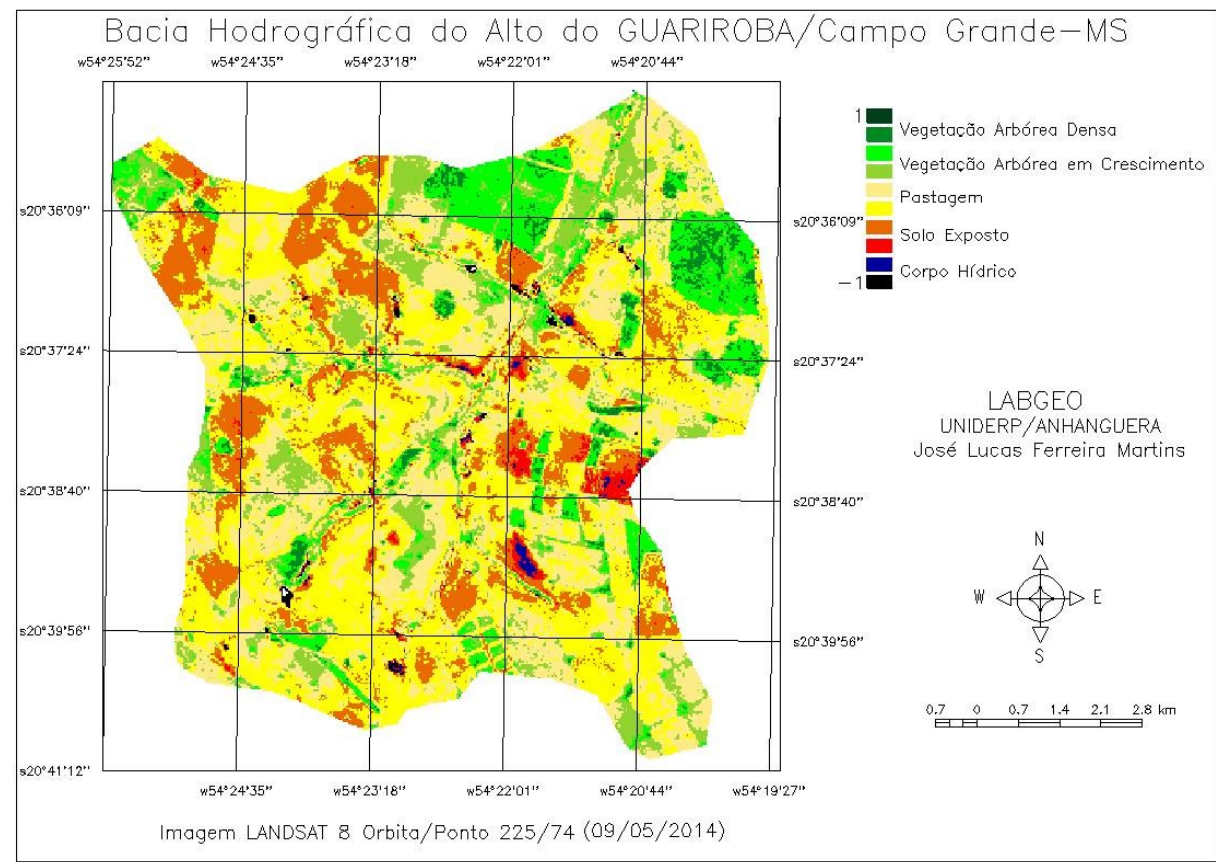

Esse resultado obtido revelam as mudanças na paisagem podem estar afetando diretamente o solo e o ambiente, expondo-os a extrema degradação de sua estrutura, podendo ocasionar erosões, poluição do solo e até o assoreamento dos recursos hídricos entre vários outros desastres, pois é nitidamente verificado, que na evolução da paisagem (Figura 5), apesar da evolução da conservação da vegetação nativa, um significativo crescimento da área sem cobertura vegetal em detrimento da diminuição das pastagens.

Com base nas cartas de Índice de Vegetação e nas classes obtidas com a análise dessas cartas é possível perceber que em 2004 a área de pastagem representava $62 \%$ da área total da APA, porém em 2014, passa a compor $60 \%$, obtendo uma perda de $2 \%$ das pastagens em dez anos de ocupação da área. Por outro lado, as áreas sem cobertura vegetal e portanto compreendendo a classe de solo exposto que compunha $12 \%$ do território estudado em 2004 , passa a ocupar $15 \%$ da bacia hidrográfica em 2014, evidenciando que a área de pastagem, historicamente provinda da atividade pecuária com deficiência de manejo na região, traz como consequência a falta de proteção do solo. 
Figura 5: Evolução do uso e ocupação do solo da bacia hidrográfica do Guariroba

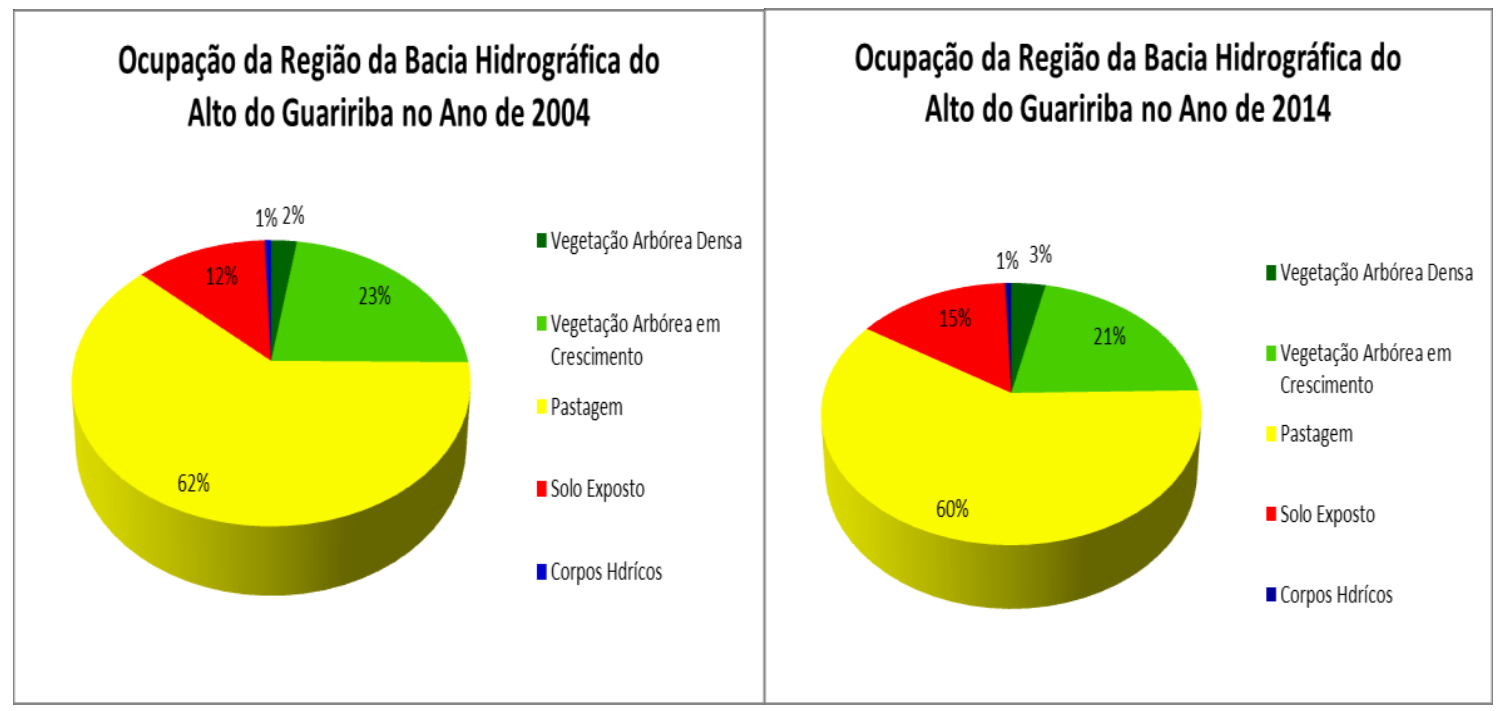

Também observa-se que, enquanto no ano de 2004 a área possuía $23 \%$ do território ocupada por vegetação em crescimento, em 2014 passou a possuir apenas $21 \%$ do território constituído desta classe, mostrando uma perda de $2 \%$ de da área de regeneração do Cerrado. No entanto, ao verificar que houve um ganho de $3 \%$. Vegetação arbórea densa, a qual ocupava 2\% da bacia hidrográfica em 2004 e passou a representar 3\% em 2014, sugere-se um indicativo de conservação das áreas de mata ciliares onde as propriedades rurais localizadas na área passaram a permitir a proteção de áreas em recuperação e regeneração do Cerrado.

Mesmo assim, a evolução da paisagem pautada no aumento do solo exposto revela o principal problema ambiental presente na Bacia hidrográfica do Alto Gurariroba e possivelmente em toda a extensão territorial da APA dos Mananciais do Guariroba.

O solo é um recurso natural não renovável, e a erosão acelerada do mesmo ocorre principalmente quando a terra fica descoberta, exposta à ação do vento e da chuva ou ainda quando submetida às secas prolongadas. A ausência de proteção de cobertura vegetal, juntamente com a das raízes, as quais estabilizam o solo, faz com que cada gota de chuva atinja o solo nu com grande impacto. Grandes partículas do solo se desprendem, e são arrastadas vertentes abaixo e depositadas no fundo dos vales, ou chegam até os mares e oceanos (COIMBRA E TIBÚRCIO, 2000). 
Para LEPSCH (2010) um solo em harmonia com o ambiente é considerado sadio, mas quando desprovido de sua vegetação natural, o solo fica exposto a uma série de fatores que tendem a depauperá-lo numa velocidade que varia com as suas características. A remoção de florestas pelo homem em áreas muito declivosas expõe o solo a erosão acelerada, onde profundos sulcos e voçorocas se abrem.

Observam-se, portanto, que na Bacia Hidrográfica do Alto Lajedo ocurreram algumas mudanças, mas ainda podemos ver indicativos de a situação ambiental é provida de riscos aos mananciais do Córrego Guariroba, o qual, uma vez pertencente a uma Área de Proteção Ambiental, deveria minimamente possuir, sobretudo suas áreas de nascentes, bem mais fiscalizadas no sentido da preservação e recuperação.

As nascentes podem ser definidas como o afloramento do lençol freático, que vai dar origem a uma fonte de água de acúmulo (represa) ou cursos d'água (ribeirões e rios). Elas se localizam em encostas ou depressões do terreno ou ainda no nível de base representado pelo curso d'água local e podem ser perenes (de fluxo contínuo), temporárias (de fluxo apenas na estação chuvosa) ou efêmeras (surgem durante as chuvas, permanecendo por apenas alguns dias ou horas) (CALHEIROS et al., 2004).

Diversos fatores podem alterar a quantidade e a qualidade da água das nascentes de uma bacia hidrográfica, como por exemplo, a declividade, o tipo e ouso do solo, principalmente das zonas de recarga, responsáveis pela drenagem da água do divisor natural até a nascente. Essa captação influencia o armazenamento da água subterrânea e o regime da nascente e dos cursos d'água. A conservação dessa água depende da conservação dos outros recursos naturais existentes no sistema (PINTO et al., 2004). 


\section{CONCLUSÃO}

Os resultados obtidos mostram que mesmo com o passar do tempo e a implantação da APA na região, deve-se tomar alguma atitude para que a situação possa ser revertida, pois os dados obtidos pelo NDVI mostram conforme que a evolução da cobertura vegetal não mostra mudanças significativas, ou seja, mesmo mostrando-se estável observa-se um aumento da classe de solo exposto em detrimento de uma diminuição das áreas de pastagens provavelmente pela falta de manejo. Portanto, conclui-se que após a implantação da APA, mesmo com plano de manejo estabelecido, as mudanças foram de pequena importância, e que em alguns pontos já houve uma degradação maior relacionada a de anos passados.

Observada a área de vegetação arbórea em crescimento, há uma pequena perda em relação aos anos comparados, já a vegetação arbórea densa teve seu pequeno crescimento, entao as mudanças ocorridas torna visivel que a APA trouxe uma pequena consientização para os moradores, os quais apenas mantiveram aquilo que já tinhamos á anos atras, portanto há ainda uma grande necessidade de incentivo e cobrança da parte dos responsaveis publicos para que a região venha a melhorar.

Segundo MAFRA (2005) a pressão exercida pela ocupação em determinadas áreas, principalmente por atividades agrícolas intensivas, aliada a uma despreocupação quanto a adoção de praticas conservacionistas, tem dado lugar a uma perda dificilmente recuperável do potencial produtivo de terras, a qual tem como causa principal a erosao acelerada.

Para SENTÍS (1993), não existem causas simples para degradação das terras por erosão, e sim uma hierarquia de causas que devem ser estudadas a distintos níveis para que possam executar politicas adequadas de uso, manejo e ocupação.

\section{REFERÊNCIAS}

CALHEIROS, R. de O. et al. Preservação e recuperação das nascentes (de água e de vida). Piracicaba: Comitê das Bacias Hidrográficas dos Rios Piracicaba, Capivari e Jundiaí, Câmara Técnica de Conservação e Proteção aos Recursos Naturais, 2004. 140 p.

COIMBRA, Pedro e TIBÚRCIO, José Arnaldo M, org. O espaço geográfico no linear do ano 2000. São Paulo Editora Harbra Ltda. 280-331 pp 2000. 
Jensen, J. R. Sensoriamento Remoto do Ambiente: Uma Perspectiva em Recursos Terrestres. Tradução de José Carlos Ephifanio (coord.) et al. São José dos Campos: Parêntese, 2009. 598 p.

MAFRA, N. M. C. Erosão e Planificação de Uso do Solo. In: GUERRA, A. J. T.; SILVA, A. S.; BOTELHO, R. G. N. (Orgs). Erosão e Conservação dos Solos: Conceitos, Temas e Aplicações. $2^{\circ}$ ed. Rio de Janeiro: Bertrand Brasil, 2005. 340p.

NOVAIS, Laíssa Rodrigues; LIMA, Amanda da Cunha; RODRIGUES, Juliana Almeida; COSTA, Anco Márcio dos Santos; BORGES, Elaine Fiuza; Anjos, Camila Souza. Análise da vegetação da Área de Preservação Ambiental de São Desidério - BA, a partir do DVI e DWI. Anais XV Simpósio Brasileiro de Sensoriamento Remoto - SBSR, Curitiba, PR, Brasil, INPE p.1888, 2011. Disponível em: < http://www.dsr.inpe.br/sbsr2011/files/p1077.pdf >. Acesso em: 09 de Agosto de 2014.

Oliveira, T. H.; Silva, J.S.; Machado, C. C. C.; Galvíncio, J. D.; Nóbrega, R. S.; Pimentel, R. M. M. Detecção espaço-temporal de estresse hídrico na vegetação do semi-árido no nordeste do Brasil utilizando DVI e DWI - Estudo de caso Serra da Capivara e Serra do Congo - PI. In: VI Seminário Latino Americano de Geografia Física, 2010, Coimbra. Disponível em <www.uc.pt/fluc/cegot/vislagf/actas/tema2/tiago > Acesso em 06 de Agosto de 2014.

PINTO, L. V. A. et al. Estudo das nascentes da bacia hidrográfica do Ribeirão Santa Cruz, Lavras, MG. Scientia Forestalis, Piracicaba, n. 65, p.197-206, jun. 2004

Ponzoni, F. J. Comportamento espectral da vegetação. In: Meneses, P. R.; Madeira Netto, J. S. (Org.).Sensoriamento remoto: reflectância dos alvos naturais. Brasília: Universidade de Brasília, 2001. 262p.

Pozoni, F. J; SHIMABUKURO, Y. E. Sensoriamento remoto no estudo da vegetação. São José dos Campos: Parêntese, 2007. 127 p.

PREFEITURA MUNICIPAL DE CAMPO GRANDE - MS; Aguas Guariroba S.A; Plano de Manejo da APA do Guariroba, v.1, 2008.

RIZZI, R. Geotecnologias em um sistema de estimativa da produção de soja: estudo de caso no Rio Grande do Sul. Tese de Doutorado do Curso de Pós-Graduação em Sensoriamento Remoto, INPE, São José dos Campos, 212 p. 2004.

ROSEMBACK, Roberta; FRANÇA, Andreia Maria Silva; FLORENZANO, Teresa Gallotti. Análise comparativa dos dados NDVI obtidos de imagens CCD/CBERS-2 e TM/LANDSAT-5 em área urbana. INPE - Instituto Nacional de Pesquisas Espaciais, São José dos Campos, SP, 2004. Disponível em: < http://www.obt.inpe.br/cbers/cbers_XIISBSR/104_paper_SBSR_urbana.pdf >. Acesso em: 09 de Agosto de 2014.

SENTÍS, P. I. (1993). Uso , Manejo y Degradación de Suelos em América Latina: situacíon actual y perspectivas de futuro. XII Congreso latino-americano de ciência del Suelo, Salamanca, Espanã.

VELASCO, Giuliana Del Nero; POLIZEL, Jefferson Lordello; COLTRI, Priscila Pereira; LIMA, Ana Maria Liner Pereira; FILHO, Demóstenes Ferreira da Silva. Aplicação Do Índice de Vegetação NDVI (Normalized Difference Vegetation Index) Em Imagens de alta resolução no Município de São Paulo e suas limitações. REVISTA DA SOCIEDADE BRASILEIRA DE ARBORIZAÇÃO URBANA, v.2, 2007.

YAMACIRO,R.M.G. O emprego do Geoprocessamento na Analise Espacial da Bacia Hidrografica do Corrego Guariroba, Campo Grande - Ms. I Anais Seminario de Recurso Hídricos da Bacia Hidrográfica do Paraíba do Sul; O Eucalipto e o ciclo Hidrológico, Taubaté, 200. p. 115-121. 